\title{
Engineering of the Cellular Translational Machinery and Non-Coding RNAs to Enhance CHO Cell Growth, Recombinant Product Yields and Quality
}

\author{
Davide Vito and C Mark Smales
}

Industrial Biotechnology Centre and School of Biosciences, University of Kent, Canterbury, Kent, CT2 7NJ, UK

Email: c.m.smales@kent.ac.uk

\begin{abstract}
Chinese hamster ovary cells are the main mammalian cell expression system currently used for the production of recombinant protein biopharmaceuticals. One of the key processes determining the achievable biomass of cells in the bioreactor and the yield and quality of recombinant protein from such systems is mRNA translation. Translation is the process by which ribosomes and associated cellular machinery decode an mRNA to produce a polypeptide. In recent years the roles of different classes of non-coding RNAs in controlling global and transcript specific mRNA translation has also come to light. Here we review approaches to engineer the translational machinery and non-coding RNAs, particularly long non-coding RNAs and tRNAs in CHO cells and then outline the challenges and potential of such approaches to revolutionize the yields and quality of recombinant protein from $\mathrm{CHO}$ and other mammalian cell expression systems.
\end{abstract}




\section{INTRODUCTION}

For the production of biopharmaceuticals, Chinese hamster ovary $(\mathrm{CHO})$ cells are the most widely used mammalian cell expression system, able to produce secretory yields of monoclonal antibody in fed-batch culture in excess of $5 \mathrm{~g} / \mathrm{L}$ [1]. The secretory yield from such an expression system is governed by the number of cells in the bioreactor across the culture (the integral of viable cell concentration or IVC) and the average amount of material expressed by each cell, usually referred to as the cell specific productivity ( $\mathrm{qP}$ ) and expressed as pg of protein/per cell/per day [2]. mRNA translation is a key cellular process that is involve in determining global and protein specific synthesis, and hence control of the abundance of proteins that constitute the cellular machinery, cell growth, division and the IVC of culture. Likewise, mRNA translation plays a key role in determining the qP of a given cell line and hence is a key regulatory process impacting on the yields and quality of recombinant protein from $\mathrm{CHO}$ cells [3].

mRNA translation is the process by which the ribosome and associated cellular machinery decodes a target mRNA to yield a polypeptide. Translation is a key step in the gene expression pathway and is the predominant process by which protein cellular abundance is controlled [4]. Over the last few decades it has been established that the control in mammalian cells of mRNA translation, and hence protein synthesis, is not only determined by the translational machinery, modulation of the activity of various translation factors by phosphorylation, and the abundance, availability and makeup of a given mRNA, but also by availability, abundance and activity of non-coding RNAs [5]. Non-coding RNAs are generally described as either long non-coding RNAs of $>200$ nucleotides in length or small non-coding RNAs $<200$ nucleotides and includes microRNAs (also referred to as miRs) and tRNAs. The discovery of the mechanism(s) by which non-coding RNAs exert an influence on gene expression has opened up new opportunities for the engineering of cells to manipulate cell processes that underpin cell growth and recombinant protein production and quality. Further, manipulation of such non-coding RNAs offers the advantage of not placing an additional translational burden on the cell that over-expression of coding mRNAs does. Here we briefly review our understanding of the control of mRNA translation in $\mathrm{CHO}$ cells, describe approaches and outcomes to engineer the translational machinery and non-coding RNAs in CHO cells, and discuss current and future cell engineering opportunities and challenges such approaches present (Summarized in Table 1).

\section{THE TRANSLATIONAL MACHINERY, mRNA ANALYSIS AND MANIPULATION}

As mRNA translation is a key process in defining cell growth, biomass accumulation and recombinant protein yields and quality from cultured $\mathrm{CHO}$ cells $[3,6]$, the translational machinery and the abundance and availability of global and recombinant mRNAs between cell lines and process conditions has been investigated using a variety of approaches. For example, the phosphorylation of the translation initiation factor elF $2 \alpha$ and attenuation of global protein synthesis during recombinant protein production in $\mathrm{CHO}$ cells is known to occur [7]. Culture temperature has been shown to impact mRNA translation and the quality of recombinant product produced [8] and the PERK-elF2 $\alpha$ pathway was reported to impact upon the aggregation of a recombinant TNFR-Fc fusion protein [9]. Indeed the activity and availability of translation factors has been shown to change during culture and under different culture conditions, where for example under reduced temperature translation elongation factor 2 (eEF2) becomes phosphorylated and a reprogramming of translation 
occurs that means transcripts with particular codon usage can escape the general global attenuation of translation under such conditions and the translation of these transcripts is actually enhanced [10].

High producing antibody cell lines have been shown to maintain translation initiation factors at levels that allow such cells to maintain enhanced recombinant protein synthesis above that of lower producing cells [3]. With regard to monoclonal antibody synthesis in $\mathrm{CHO}$ and other cells, investigations have shown that recombinant antibody production is limited by translational efficiency [3,11-13]. Manipulation of the cellular translational machinery is however, not straightforward. One global regulator of ribosome biogenesis and translation is mTORC1, which coordinates cellular responses to signaling pathways involved in sensing growth factors, nutrient availability, intracellular energy status and other perceived cell stresses and modulates translation and ribosome biogenesis in response [14]. In particular, mTORC1 can influence translation initiation via phosphorylation of eukaryotic initiation factor $4 \mathrm{E}$ binding protein (4E-BP1), which when phosphorylated at multiple sites promotes dissociation of 4E-BP1 from the initiation factor elF4E. Increased phosphorylation of 4E-BP1 has been correlated with increased interferon$\gamma$ production [15] whilst the stoichiometry of $4 \mathrm{E}-\mathrm{BP} 1$ to elF4E is reported to relate to recombinant antibody productivity [16]. Exogenous $\mathrm{mTOR}$ expression has also been shown to enhance recombinant protein expression in $\mathrm{CHO}$ cells by improving cell viability, growth, proliferation and cell specific productivity [17].

One approach applied to investigate mRNA amounts, and hence determine gene expression profiles of high producing or fast growing recombinant cell lines is transcriptomics. A general assumption of most such studies is that the amount of mRNA present at a given timepoint reflects the 'state' or 'need' of a cell with regard to the proteins that these mRNAs encode for. As such, transcriptomic profiling has been applied to identify mRNAs whose abundance correlates with cell growth and recombinant protein productivity and quality with a view to using the identification of such targets to engineer the cell for improved performance. Many of these initial studies were hampered by the lack of the $\mathrm{CHO}$ genome and appropriate arrays, however the elucidation of the genome $[18,19]$ and advent of RNA-Seq has made it possible to undertake such studies with a higher degree of precision. Despite this, there has been little consensus across transcriptomic studies to date with regard to those mRNAs that correlate with cell growth and recombinant protein productivity [20]. Further, previous correlation analysis has shown that transcript amounts and translation efficiency are uncoupled for around $95 \%$ of investigated genes [21], providing strong evidence that global and mRNA specific translational control needs to be understood and determined to evaluate the impact of mRNAs on phenotype rather than simple mRNA abundance itself.

In order to address this issue, investigators have begun to apply ribosome footprint profiling or RiboSeq analysis to unravel the fine detail of translational control in $\mathrm{CHO}$ cells [22]. This powerful approach allows genome wide, but also transcript specific, detail on initiation and elongation stages of mRNA translation to be studied and identification of those mRNAs that are being translated at any given time (as opposed to just their abundance), the efficiency of mRNA translation and how this changes during a process or between cell lines to identify targets for cell line engineering [22]. Indeed, any given mRNA in the cell may be translated by one or multiple ribosomes (so call polysomes) at any one 
time [23]. In some cases the number of ribosomes per transcript has been used to estimate translational efficiency of a transcript assuming that more ribosomes on a transcript indicates greater translational efficiency [24], but this does not account for elongation speed that RiboSeq analysis can. RNA-Seq approaches can also potentially be used to investigate translational activity at the single cell level. The application of such approaches is certain to provide a more detailed understanding of mRNA translation and its control in recombinant protein producing $\mathrm{CHO}$ cells, at the population and single cell level and at a global and transcript specific level, revealing new engineering approaches by which translation can be modulated to enhance protein production.

\section{microRNAs and siRNAs}

mRNA translation can also be tuned by non-coding RNAs. One such class of non-coding RNA that has been applied to reprogramming translation in $\mathrm{CHO}$ cells is that of microRNAs (also known as miRs or miRNAs). The potential application of microRNAs to $\mathrm{CHO}$ cell engineering has recently been reviewed elsewhere [25]. These RNAs are transcribed as long primary transcripts but then processed to yield small (20-23 nucleotide) non-coding RNAs and were first described in C. elegans. MicroRNAs tend to act as repressors of translation of target mRNAs by interacting with the 3'untranslated regions (3'UTRs) of such mRNAs. A given microRNA can in theory target multiple mRNAs via base pairing and hence modulate multiple mRNAs and pathways without placing an additional translational burden on the cell [25].

Early microRNA studies were limited by the lack of available Chinese hamster sequence annotation of microRNA primary transcripts, and hence chimeric microRNAs that contained the mature miR sequence but flanking sequences in the primary transcript from other species were used. Subsequent studies showed that endogenous $\mathrm{CHO}$ microRNA flanking sequences gave rise to higher expression when over-expressing microRNAs [26]. Recent engineering approaches harnessing microRNAs include studies that look to enhance the ability of $\mathrm{CHO}$ cells to produce so called 'difficult to express proteins'. For example, one such study showed that a $\mathrm{CHO}$ cell line constitutively over-expressing miR-557 and a difficult to express antibody produced twice the antibody yield of cells engineered to express a negative control microRNA [27]. A further study reported that both transient and stable miR-143 over-expression resulted in enhanced difficult to express protein production and targeted MAPK7 in $\mathrm{CHO}$ [28]. The natural repertoire of microRNAs has also been harnessed to repress expression of the DHFR selection marker during cell line construction and allow the generation of higher producing cell pools [29]. Others have shown that microRNA fingerprints or signatures can be correlated with growth rate across a number of different $\mathrm{CHO}$ cell lines [30].

However, although microRNA engineering appears an attractive approach by which to tune translation of multiple mRNAs and translation of specific targets, the potential large number of predicted targets of any given microRNA means that the outcome of such engineering approaches can be difficult to predict as is identifying which targets a given microRNA interacts with. Barron and colleagues have described a system termed 'miRCATCH' that allows the investigator to identify those microRNAs that interact with a given target and thus validate these for potential cell engineering approaches [31•]. The authors had identified that the overexpression of the X-linked inhibitor of apoptosis (XIAP) enhanced $\mathrm{CHO}$ cell productivity, growth and culture longevity. To avoid overexpressing this 
gene and placing an additional translational burden on the cell, microRNA regulators of XIAP were identified using a biotin-labelled antisense DNA for XIAP resulting in the capture of interacting microRNAs. Inhibition of two of these microRNAs resulted in increased XIAP protein expression, validating the microRNA catch approach and the utility of this for identifying cell engineering targets.

The use of small interfering RNAs (siRNAs) has also proved to be an effective strategy for $\mathrm{CHO}$ cell line engineering to selectively knockdown expression of target genes detrimental to cell growth or productivity. The advantage of knockdown, as opposed to knockout strategies, is that essential genes can be reduced in their expression and the impact on cell phenotype assessed when knockout proves fatal. One successful application of siRNA engineering has been the inhibition of lactate dehydrogenase-A (LDH-A) on its own [32], or in combination with pyruvate dehydrogenase kinases (PDHKs) [33] to significantly reduce lactate accumulation in cultured $\mathrm{CHO}$ cells without negatively impacting cell growth and enhancing cell specific productivity. A further group undertook ribosomal profiling in $\mathrm{CHO}$ cells and identified the resistance marker NeoR as being highly transcribed and translated, and as expression of this exogenous gene in $\mathrm{CHO}$ cells is not required, used siRNA knockdown to reduce its expression with a resultant improvement in production and growth of the host observed [34]. Finally, an siRNA approach was used to knockdown the expression of the endoplasmic reticulum localized proteins ceramide synthase 2 (CerS2) and Rab1 GAP Tbc domain family member 20 (Tbc1D20) in CHO IgG producing cells with a subsequent observed increase in recombinant protein specific productivity and enhanced cell growth [35].

\section{LONG NON-CODING RNAs (InCRNAs) AND THEIR MANIPULATION}

Recent genome wide analysis in mammalian cells estimates that $75 \%$ of the transcriptome is composed of non-coding sequences [36] and led to the identification of a heterogeneous class of transcripts known as Long non-coding RNAs (IncRNAs) [37]. LncRNAs are defined as transcripts longer than 200 nucleotides that lack a significant open reading frame (ORF) and are usually transcribed by RNA polymerase II and spliced, with or without, 3' polyadenylation [38]. These molecules are emerging as key regulators in various biological processes both in the nucleus and the cytoplasm [39], including epigenetic regulation, transcriptional control, splicing events, and mRNA translation. While most of our current understanding into IncRNAs and the underlying mechanism(s) by which they elicit their responses has come from studies relating to disease and developmental studies, their potential as targets for cell engineering in mammalian cell factories remains largely unexplored.

The first analysis of the non-coding transcriptome in $\mathrm{CHO}$ cells under batch and fed-batch conditions has recently been published, unveiling a number of differentially regulated IncRNAs depending on feed and culture time which could be targets for cell engineering [40•]. One of the main challenges in identifying IncRNAs is the low sequence conservation between species. This, coupled with incomplete genome sequences and partial annotations of coding and non-coding genes of most vertebrates including Chinese hamster, have impaired an effective IncRNAs annotation outside from model organisms (Figure 1).

A recent study compared IncRNAs among 16 vertebrates and the echinoid sea urchin finding thousands of human lincRNAs homologs with conserved genomic position sharing 5 '-biased patches of sequence nested in rewired exonic architectures [41]. The FANTOM consortium applied a cap analysis of gene expression (CAGE) to data obtaining more than 27,919 human 
IncRNA genes with high-confidence $5^{\prime}$ ends and expression profiles across 1,829 samples from the major human primary cell types and tissues [42]. Through the incorporation of conservation and expression data, the consortium was able to identify 19,175 potentially functional IncRNAs in the human genome. Due to the tissue-specificity of IncRNAs, comparing the expression among several cell types has led to a more robust identification of functional targets. By modelling their effects on the activity of transcription factors, RNA-binding proteins, and microRNAs in 5,185 TCGA tumors and 1,019 ENCODE assays, it was possible to identify potential IncRNAs involved in dysregulated cancer pathways. This approach indicated OIP5-AS1, TUG1, NEAT1, MEG3, and TSIX, as synergic IncRNAs leading to dysregulated cancer pathways in multiple tumor contexts [43]. A similar effort using nascent RNA capture sequencing identified 1145 temporally expressed S-phase-enriched IncRNAs across TCGA data sets in several cancer models showing effects on pathways including FGF/FGFR and its downstream PI3K/AKT and MAPK pathways [44].

The NEAT1 IncRNA is a central component of paraspeckles, nuclear bodies that regulate multiple aspects of gene expression, promoting their formation through ATR signaling in response to replication stress and p53 activation [45]. The RNA-binding NONO-PSF heterodimer binds a large number of expressed pri-miRNAs in the paraspeckles to promote processing by the Drosha-DGCR8 Microprocessor. NEAT1 thus regulates efficient processing of potentially an entire class of small non-coding RNAs in the nucleus by interaction with the NONO-PSF heterodimer as well as other ribosome binding proteins (RBPs) [46].

The relationship between IncRNAs and the translational machinery was further elucidated with the discovery of a long nucleolus-specific IncRNA (LoNA) [47•]. LoNA is expressed at high levels at resting state suppressing rRNAs transcription in the nucleoli through the combined effects of its $5^{\prime}$ portion, which binds and sequesters nucleolin, and its snoRNA like $3^{\prime}$ end, which recruits and diminishes fibrillarin activity to reduce rRNA methylation. When the cell needs to sustain an elevated translational load, LoNA expression decreases leading to elevated rRNA and ribosome levels, an increased proportion of polysomes, mRNA polysome loading, and eventually protein synthesis.

The first successful engineering of IncRNAs for enhanced recombinant protein production involved manipulation of SINEUPs, natural and synthetic antisense IncRNAs that can activate translation in a gene-specific manner using an inverted SINEB2 sequence [48]. A Binding Domain (BD) located towards the $5^{\prime}$ region of the SINEUP overlaps a target mRNA of choice conferring specificity, while an inverted SINEB2 element defined as the Effector Domain (ED) provides the translation activation function [49]. Synthetic SINEUPs have been used to increase translation and secretion of recombinant proteins in a range of mammalian cell lines, including $\mathrm{CHO}$ [50••] and HEK293 [51•]. As further studies define those IncRNAs present in $\mathrm{CHO}$ cells and how these influence cell growth, fate and recombinant protein production, engineering of these non-coding RNAs is sure to offer potential to further tune and enhance mRNA specific and global mRNA translational efficiency.

\section{tRNAs AND TRANSLATION}

The use of specific codons with high gene copy number and high codon bias coupled with the modulation of intracellular tRNA concentration has been shown to improve protein production in $\mathrm{CHO}$ cells [52]. However, despite translational efficiency often being considered the mere result of codon optimization based on the correlation between codon bias and tRNA gene copy numbers (Figure 2), recent evidence suggests a considerably more 
intricate picture where ribosome collisions, co-translational folding, mRNA stability, composition, charge status and post-transcriptional modifications of the tRNA pool all contribute to finely tune protein production in response to the environment [53]. Controlling the translational capacity of an expression system through the use of alternative codon combinations modulates ribosome decoding speed, impacting protein quality as well as final yield [54]. The use of suboptimal codons has been reported to slow translation at key structural motifs in order to facilitate correct co-translational polypeptide folding and signal recognition particle (SRP) recognition, which assists in protein translocation across membranes [55]. Thus, although recombinant genes are often 'codon optimized', we do not currently have all the information required around codon usage, context, tRNA abundance, modifications and charging to fully harness codon usage in recombinant sequences or to engineer tRNA abundance.

Codon bias has been referred to as a secondary genetic code that impacts on the fidelity of translation, efficiency of translation, polypeptide/protein folding and mRNA stability/half-life [56]. The cell utilizes such codon effects to tailor the proteome and allow reprogramming, such as under cold stress whereby reprogramming and synthesis of specific proteins is enhanced through codon bias [10]. Codon bias or optimization is also linked to tuning mRNA stability and stable mRNAs are found to be enriched in codons that are considered optimal whilst also impacting on ribosome translocation [57]. Specific combinations of adjacent codons in yeast and mammalian cells can have an effect on translation efficiency resulting in reduced expression, proving how the focus must be on global translation efficiency and codon context as opposed to single codons optimality [58•$60]$. On top of this, mRNA secondary structure combined with tRNA abundance modulate translational elongation speed among different regions of the same transcript to avoid excessively slow or fast ribosome movement [61]. As such, there remains enormous potential to enhance recombinant protein yields from further manipulation of codon usage.

In order to further enhance recombinant protein yields by manipulation of codon usage it is necessary to further understand the abundance and modifications of tRNAs and the role these play in their activity. Determination of tRNA copy numbers can now be undertaken using RNA-Seq approaches. tRNA secondary structure and nucleotide modifications, mainly methylations, impair the efficiency of standard sequencing. Dedicated protocols based on an initial de-methylation step were recently developed to overcome this limitation, allowing for direct measurement of each tRNA abundance and detailed mapping of modifications $[62,63]$. While some methods focus exclusively on mature tRNAs [64], partial alkaline RNA hydrolysis complemented with tRNA precursors enrichment identified tRNA leaders, trailers, and introns and showed that around half of all predicted tRNA genes are transcribed in human cells [65]. While tRNA abundance is a major modulator of translational elongation, the aminoacylation state has to also be considered. The addition of chemical steps that specifically remove the $3^{\prime} A$ residue in uncharged tRNA coupled with the aforementioned de-methylation RNA-Seq protocols showed most cytosolic tRNAs in HEK293T cells are charged at $>80 \%$ levels, whereas tRNASer and tRNAThr are charged at lower levels [66].

An additional layer of regulation during elongation is chemical modification of nucleotides among tRNAs [67]. One of the key enzymes to regulate the methylation state of tRNAs is the demethylase ALKBH1, which acts dynamically in response to specific conditions such as variations in glucose availability to impact translation at both the initiation and the elongation 
phases [68]. These modifications can have different effects depending on the target tRNA and the position in the transcript, as it was shown ALKBH1 is required for the formation of essential methylations at position 34 of anticodon in cytoplasmic tRNALeu and mitochondrial tRNAMet [69]. Advances in high-throughput sequencing and data analysis have also allowed the identification of new classes of small non-coding RNAs derived from tRNAs: stressinduced tRNA halves (tiRs) and tRNA-related fragments (tRFs). These RNAs act on cell proliferation, priming of viral reverse transcriptase, regulation of gene expression, RNA processing, modulation of the DNA damage response, tumor suppression, and stress response [70]. The application of such approaches to study tRNAs in $\mathrm{CHO}$ cells will further elucidate the mechanism(s) by which tRNAs and their modifications modulate translation.

\section{FUTURE DIRECTIONS AND CHALLENGES}

Our understanding and ability to manipulate the translational machinery and harness noncoding RNAs to enhance global and recombinant protein synthesis in $\mathrm{CHO}$ cells has advanced rapidly in the last decade. Further, the advent of the Chinese hamster and $\mathrm{CHO}$ cell line genomes has helped in the identification of non-coding RNAs such that these can be studied and manipulated. The ability of non-coding RNAs, in particular microRNAs, siRNAs, IncRNAs and tRNAs to tune both global and transcript specific translation, and hence protein synthesis, offers enormous opportunities to use these to enhance cell growth and proliferation, extend culture lifetimes, and increase recombinant protein yields and quality. However, our ability to harness these non-coding RNAs by engineering of $\mathrm{CHO}$ cells is currently limited by our knowledge of the mechanisms and targets by which many of these non-coding RNAs elicit their responses. The manipulation of microRNAs that can, in theory, tune multiple target transcripts appears an appealing approach, however in our view this approach alone is unlikely to deliver new commercially viable host cells with dramatically enhanced phenotypes due to the fact these are 'tuning' molecules and tend to be negative regulators and off target approaches can be difficult to control. Where these might be more applicable is for the tuning of transcript targets with a specific role, such as enzymes involved in glycosylation or to harness modulation of the cells own endogenous microRNA pool as inducible controllers of exogenous gene circuits. The potential of IncRNA engineering is very much in its infancy and would appear to offer the potential to act as negative and positive regulators of gene expression. The limitation here is that many of these are, as the name suggests, long RNAs and thus the manipulation is more challenging and we do not yet understand what, if any, role many of these play in the cell. The control of gene expression via the elongation step of mRNA translation and tRNA availability, charging and modification, linked with improved predictive models for how such changes in abundance or modification change elongation rates of target mRNAs is likely to offer advances that can be directly applied industrially to engineering of the target recombinant gene(s) and of pathways in the cell to deliver new engineered host cell lines with improved growth, productivity and post-translational modification abilities. However, the major challenge will be to unravel the mechanisms by which the control on gene expression that these different non-coding RNAs provide are coordinated together, in order to reprogram the translational efficiency of current $\mathrm{CHO}$ cell chassis, under appropriate bioprocessing conditions (including continuous processes) to generate new chassis with enhance bioprocessing properties.

\section{ACKNOWLEDGEMENTS}


The authors acknowledge the European Commission for funding this work (EC - Horizon 2020 MSCA ITN 2014 - 642663).

\section{REFERENCES AND RECOMMENDED READING}

[1] J.F. Povey, C.J. O'Malley, T. Root, E.B. Martin, G.A. Montague, M. Feary, C. Trim, D.A. Lang, R. Alldread, A.J. Racher, C.M. Smales, Rapid high-throughput characterisation, classification and selection of recombinant mammalian cell line phenotypes using intact cell MALDI-ToF mass spectrometry fingerprinting and PLS-DA modelling, J. Biotechnol. 184 (2014) 84-93. doi:10.1016/j.jbiotec.2014.04.028.

[2] R. Kunert, D. Reinhart, Advances in recombinant antibody manufacturing, Appl. Microbiol. Biotechnol. 100 (2016) 3451-61. doi:10.1007/s00253-016-7388-9.

[3] E.J. Mead, R.J. Masterton, M. Feary, O. Obrezanova, L. Zhang, R. Young, C.M. Smales, Biological insights into the expression of translation initiation factors from recombinant CHOK1SV cell lines and their relationship to enhanced productivity, Biochem. J. 472 (2015) 261-73. doi:10.1042/BJ20150928.

[4] B. Schwanhäusser, D. Busse, N. Li, G. Dittmar, J. Schuchhardt, J. Wolf, W. Chen, M. Selbach, Global quantification of mammalian gene expression control, Nature. 473 (2011) 337-342. doi:10.1038/nature10098.

[5] H. Janakiraman, R.P. House, V.K. Gangaraju, J.A. Diehl, P.H. Howe, V. Palanisamy, The long (IncRNA) and short (miRNA) of it: TGF $\beta$-mediated control of RNA-binding proteins and noncoding RNAs, Mol. Cancer Res. 16 (2018) 567-579. doi:10.1158/15417786.MCR-17-0547.

[6] J. McLeod, P.M. O'Callaghan, L.P. Pybus, S.J. Wilkinson, T. Root, A.J. Racher, D.C. James, An empirical modeling platform to evaluate the relative control discrete $\mathrm{CHO}$ cell synthetic processes exert over recombinant monoclonal antibody production process titer, Biotechnol. Bioeng. 108 (2011) 2193-204. doi:10.1002/bit.23146.

[7] M.F. Underhill, J.R. Birch, C.M. Smales, L.H. Naylor, elF2 $\alpha$ phosphorylation, stress perception, and the shutdown of global protein synthesis in cultured $\mathrm{CHO}$ cells, Biotechnol. Bioeng. 89 (2005) 805-814. doi:10.1002/bit.20403.

[8] R.J. Masterton, A. Roobol, M.B. Al-Fageeh, M.J. Carden, C.M. Smales, Post-translational events of a model reporter protein proceed with higher fidelity and accuracy upon mild hypothermic culturing of Chinese hamster ovary cells., Biotechnol. Bioeng. 105 (2010) 215-20. doi:10.1002/bit.22533.

[9] K. Wang, T. Zhang, J. Chen, C. Liu, J. Tang, Q. Xie, The effect of culture temperature on the aggregation of recombinant TNFR-Fc is regulated by the PERK-elF2a pathway in CHO cells, Protein Pept. Lett. 25 (2018) 570-579. doi:10.2174/0929866525666180530121317.

[10] A. Bastide, D. Peretti, J.R.P. Knight, S. Grosso, R. V Spriggs, X. Pichon, T. Sbarrato, A. Roobol, J. Roobol, D. Vito, M. Bushell, T. von der Haar, C.M. Smales, G.R. Mallucci, A.E. Willis, RTN3 is a novel cold-induced protein and mediates neuroprotective effects of RBM3, Curr. Biol. 27 (2017) 638-650. doi:10.1016/j.cub.2017.01.047. 
[11] E.J. Mead, L.M. Chiverton, S.K. Spurgeon, E.B. Martin, G.A. Montague, C.M. Smales, T. von der Haar, Experimental and in silico modelling analyses of the gene expression pathway for recombinant antibody and by-product production in NSO cell lines, PLoS One. 7 (2012) e47422. doi:10.1371/journal.pone.0047422.

[12] A. Roobol, J. Roobol, A. Bastide, J.R.P. Knight, A.E. Willis, C.M. Smales, p58IPK is an inhibitor of the elF2 $\alpha$ kinase GCN2 and its localization and expression underpin protein synthesis and ER processing capacity, Biochem. J. 465 (2015) 213-25. doi:10.1042/BJ20140852.

[13] P.M. O'Callaghan, J. McLeod, L.P. Pybus, C.S. Lovelady, S.J. Wilkinson, A.J. Racher, A. Porter, D.C. James, Cell line-specific control of recombinant monoclonal antibody production by $\mathrm{CHO}$ cells, Biotechnol. Bioeng. 106 (2010) 938-951. doi:10.1002/bit.22769.

[14] K.G. Foster, D.C. Fingar, Mammalian target of rapamycin (mTOR): conducting the cellular signaling symphony, J. Biol. Chem. 285 (2010) 14071-7. doi:10.1074/jbc.R109.094003.

[15] W.P.K. Chong, L.C. Sim, K.T.K. Wong, M.G.S. Yap, Enhanced IFNgamma production in adenosine-treated CHO cells: a mechanistic study, Biotechnol. Prog. 25 (2009) 866-73. doi:10.1002/btpr.118.

[16] L. Jossé, J. Xie, C.G. Proud, C.M. Smales, mTORC1 signalling and elF4E/4E-BP1 translation initiation factor stoichiometry influence recombinant protein productivity from GS-CHOK1 cells, Biochem. J. 473 (2016) 4651-4664. doi:10.1042/BCJ20160845.

[17] I.A.J. Dreesen, M. Fussenegger, Ectopic expression of human mTOR increases viability, robustness, cell size, proliferation, and antibody production of chinese hamster ovary cells, Biotechnol. Bioeng. 108 (2011) 853-66. doi:10.1002/bit.22990.

[18] X. Xu, H. Nagarajan, N.E. Lewis, S. Pan, Z. Cai, X. Liu, W. Chen, M. Xie, W. Wang, S. Hammond, M.R. Andersen, N. Neff, B. Passarelli, W. Koh, H.C. Fan, J. Wang, Y. Gui, K.H. Lee, M.J. Betenbaugh, S.R. Quake, I. Famili, B.O. Palsson, J. Wang, The genomic sequence of the Chinese hamster ovary (CHO)-K1 cell line, Nat. Biotechnol. (2011). doi:10.1038/nbt.1932.

[19] N.E. Lewis, X. Liu, Y. Li, H. Nagarajan, G. Yerganian, E. O’Brien, A. Bordbar, A.M. Roth, J. Rosenbloom, C. Bian, M. Xie, W. Chen, N. Li, D. Baycin-Hizal, H. Latif, J. Forster, M.J. Betenbaugh, I. Famili, X. Xu, J. Wang, B.O. Palsson, Genomic landscapes of Chinese hamster ovary cell lines as revealed by the Cricetulus griseus draft genome, Nat. Biotechnol. (2013). doi:10.1038/nbt.2624.

[20] L. Tamošaitis, C.M. Smales, Meta-Analysis of Publicly Available Chinese Hamster Ovary (CHO) Cell Transcriptomic Datasets for Identifying Engineering Targets to Enhance Recombinant Protein Yields, Biotechnol. J. (2018) e1800066. doi:10.1002/biot.201800066.

[21] F.C. Courtes, J. Lin, H.L. Lim, S.W. Ng, N.S.C. Wong, G. Koh, L. Vardy, M.G.S. Yap, B. Loo, D.-Y. Lee, Translatome analysis of $\mathrm{CHO}$ cells to identify key growth genes, J. Biotechnol. 167 (2013) 215-224. doi:10.1016/j.jbiotec.2013.07.010. 
[22] I. Tzani, C. Monger, P. Kelly, N. Barron, R.M. Kelly, C. Clarke, Understanding biopharmaceutical production at single nucleotide resolution using ribosome footprint profiling, Curr. Opin. Biotechnol. $53 \quad$ (2018) 182-190. doi:10.1016/j.copbio.2018.01.030.

[23] C.L. Godfrey, E.J. Mead, O. Daramola, S. Dunn, D. Hatton, R. Field, G. Pettman, C.M. Smales, Polysome profiling of $\mathrm{mAb}$ producing $\mathrm{CHO}$ cell lines links translational control of cell proliferation and recombinant mRNA loading onto ribosomes with global and recombinant protein synthesis, Biotechnol. J. $12 \quad$ (2017) 1700177. doi:10.1002/biot.201700177.

[24] B. Liu, S.-B. Qian, Characterizing inactive ribosomes in translational profiling., Transl. (Austin, Tex.). 4 (2016) e1138018. doi:10.1080/21690731.2015.1138018.

[25] R. Valdés-Bango Curell, N. Barron, Exploring the potential application of short noncoding RNA-based genetic circuits in Chinese hamster ovary cells, Biotechnol. J. (2018) 1700220. doi:10.1002/biot.201700220.

[26] G. Klanert, V. Jadhav, K. Chanoumidou, J. Grillari, N. Borth, M. Hackl, Endogenous microRNA clusters outperform chimeric sequence clusters in Chinese hamster ovary cells, Biotechnol. J. 9 (2014) 538-44. doi:10.1002/biot.201300216.

[27] S. Fischer, K.F. Marquart, L.A. Pieper, J. Fieder, M. Gamer, I. Gorr, P. Schulz, H. Bradl, miRNA engineering of $\mathrm{CHO}$ cells facilitates production of difficult-to-express proteins and increases success in cell line development, Biotechnol. Bioeng. 114 (2017) 14951510. doi:10.1002/bit.26280.

[28] M. Schoellhorn, S. Fischer, A. Wagner, R. Handrick, K. Otte, miR-143 targets MAPK7 in $\mathrm{CHO}$ cells and induces a hyperproductive phenotype to enhance production of difficultto-express proteins, Biotechnol. Prog. 33 (2017) 1046-1058. doi:10.1002/btpr.2475.

[29] L. Jossé, L. Zhang, C.M. Smales, Application of microRNA targeted 3'UTRs to repress DHFR selection marker expression for development of recombinant antibody expressing CHO cell pools, Biotechnol. J. (2018). doi:10.1002/biot.201800129.

[30] G. Klanert, V. Jadhav, V. Shanmukam, A. Diendorfer, M. Karbiener, M. Scheideler, J.H. Bort, J. Grillari, M. Hackl, N. Borth, A signature of 12 microRNAs is robustly associated with growth rate in a variety of CHO cell lines, J. Biotechnol. 235 (2016) 150-161. doi:10.1016/j.jbiotec.2016.03.022.

[31•] A. Griffith, P.S. Kelly, S. Vencken, N.T. Lao, C.M. Greene, M. Clynes, N. Barron, miRCATCH identifies biologically active miRNA regulators of the pro-survival gene XIAP, in Chinese hamster ovary cells, Biotechnol. J. $13 \quad$ (2018) 1700299. doi:10.1002/biot.201700299.

The authors developed a system to identify and validate microRNAs that target a specific mRNA and used this to identify microRNAs that negatively regulate the prosurvival gene XIAP. They subsequeuntly show that reducing or inhibiting two of the microRNAs that target this transcript resulted in enhanced XIAP expression and prolonged culture duration.

[32] S.H. Kim, G.M. Lee, Down-regulation of lactate dehydrogenase-A by siRNAs for reduced 
lactic acid formation of Chinese hamster ovary cells producing thrombopoietin, Appl. Microbiol. Biotechnol. 74 (2007) 152-9. doi:10.1007/s00253-006-0654-5.

[33] M. Zhou, Y. Crawford, D. Ng, J. Tung, A.F.J. Pynn, A. Meier, I.H. Yuk, N. Vijayasankaran, K. Leach, J. Joly, B. Snedecor, A. Shen, Decreasing lactate level and increasing antibody production in Chinese Hamster Ovary cells $(\mathrm{CHO})$ by reducing the expression of lactate dehydrogenase and pyruvate dehydrogenase kinases, J. Biotechnol. 153 (2011) 27-34. doi:10.1016/j.jbiotec.2011.03.003.

[34] T.B. Kallehauge, S. Li, L.E. Pedersen, T.K. Ha, D. Ley, M.R. Andersen, H.F. Kildegaard, G.M. Lee, N.E. Lewis, Ribosome profiling-guided depletion of an mRNA increases cell growth rate and protein secretion, Sci. Rep. 7 (2017) 40388. doi:10.1038/srep40388.

[35] L.A. Pieper, M. Strotbek, T. Wenger, M. Gamer, M.A. Olayioye, A. Hausser, Secretory pathway optimization of $\mathrm{CHO}$ producer cells by co-engineering of the mitosRNA-1978 target genes CerS2 and Tbc1D20, Metab. Eng. 40 (2017) 69-79. doi:10.1016/j.ymben.2017.01.003.

[36] S. Djebali, C.A. Davis, A. Merkel, A. Dobin, T. Lassmann, A. Mortazavi, A. Tanzer, J. Lagarde, W. Lin, F. Schlesinger, C. Xue, G.K. Marinov, J. Khatun, B.A. Williams, C. Zaleski, J. Rozowsky, M. Röder, F. Kokocinski, R.F. Abdelhamid, T. Alioto, I. Antoshechkin, M.T. Baer, N.S. Bar, P. Batut, K. Bell, I. Bell, S. Chakrabortty, X. Chen, J. Chrast, J. Curado, T. Derrien, J. Drenkow, E. Dumais, J. Dumais, R. Duttagupta, E. Falconnet, M. Fastuca, K. Fejes-Toth, P. Ferreira, S. Foissac, M.J. Fullwood, H. Gao, D. Gonzalez, A. Gordon, H. Gunawardena, C. Howald, S. Jha, R. Johnson, P. Kapranov, B. King, C. Kingswood, O.J. Luo, E. Park, K. Persaud, J.B. Preall, P. Ribeca, B. Risk, D. Robyr, M. Sammeth, L. Schaffer, L.-H. See, A. Shahab, J. Skancke, A.M. Suzuki, H. Takahashi, H. Tilgner, D. Trout, N. Walters, H. Wang, J. Wrobel, Y. Yu, X. Ruan, Y. Hayashizaki, J. Harrow, M. Gerstein, T. Hubbard, A. Reymond, S.E. Antonarakis, G. Hannon, M.C. Giddings, Y. Ruan, B. Wold, P. Carninci, R. Guigó, T.R. Gingeras, Landscape of transcription in human cells, Nature. 489 (2012) 101-108. doi:10.1038/nature11233.

[37] P. Kapranov, J. Cheng, S. Dike, D.A. Nix, R. Duttagupta, A.T. Willingham, P.F. Stadler, J. Hertel, J. Hackermuller, I.L. Hofacker, I. Bell, E. Cheung, J. Drenkow, E. Dumais, S. Patel, G. Helt, M. Ganesh, S. Ghosh, A. Piccolboni, V. Sementchenko, H. Tammana, RNA maps reveal new RNA classes and a possible function for pervasive transcription, Science. 316 (2007) 1484-1488. doi:10.1126/science.1138341.

[38] J.E. Wilusz, Long noncoding RNAs: re-writing dogmas of RNA processing and stability, Biochim. Biophys. Acta. 1859 (2016) 128-138. doi:10.1016/j.bbagrm.2015.06.003.

[39] S. Geisler, J. Coller, RNA in unexpected places: long non-coding RNA functions in diverse cellular contexts, Nat. Rev. Mol. Cell Biol. 14 (2013) 699-712. doi:10.1038/nrm3679.

[40•] D. Vito, C.M. Smales, The long non-coding RNA transcriptome landscape in CHO cells under batch and fed-batch conditions., Biotechnol. J. (2018) e1800122. doi:10.1002/biot.201800122.

This is the first report of the global IncRNA transcritpome landscape in CHO cells, using an array approach to identify the presence of IncRNAs, qPCR to confirm the array results on selected transcripts and demonstrates how these change during batch and 
fed-batch culture.

[41] H. Hezroni, D. Koppstein, D.P. Bartel, I. Ulitsky Correspondence, M.G. Schwartz, A. Avrutin, I. Ulitsky, Principles of long noncoding RNA evolution derived from direct comparison of transcriptomes in 17 species, Cell Rep. 11 (2015) 1110-1122. doi:10.1016/j.celrep.2015.04.023.

[42] C.C. Hon, J.A. Ramilowski, J. Harshbarger, N. Bertin, O.J.L. Rackham, J. Gough, E. Denisenko, S. Schmeier, T.M. Poulsen, J. Severin, M. Lizio, H. Kawaji, T. Kasukawa, M. Itoh, A.M. Burroughs, S. Noma, S. Djebali, T. Alam, Y.A. Medvedeva, A.C. Testa, L. Lipovich, C.W. Yip, I. Abugessaisa, M. Mendez, A. Hasegawa, D. Tang, T. Lassmann, P. Heutink, M. Babina, C.A. Wells, S. Kojima, Y. Nakamura, H. Suzuki, C.O. Daub, M.J.L. De Hoon, E. Arner, Y. Hayashizaki, P. Carninci, A.R.R. Forrest, An atlas of human long noncoding RNAs with accurate $5^{\prime}$ ends, Nature. 543 (2017) 199-204. doi:10.1038/nature21374.

[43] H.-S. Chiu, S. Somvanshi, E. Patel, A.K. Sood, P.H. Gunaratne, P.S. Correspondence, T.W. Chen, V.P. Singh, B. Zorman, S.L. Patil, Y. Pan, S.S. Chatterjee, P. Sumazin, PanCancer analysis of IncRNA regulation supports their targeting of cancer genes in each tumor context, Cell Rep. 23 (2018) 297-312. doi:10.1016/j.celrep.2018.03.064.

[44] M.M. Ali, V.S. Akhade, S.T. Kosalai, S. Subhash, L. Statello, M. Meryet-Figuiere, J. Abrahamsson, T. Mondal, C. Kanduri, PAN-cancer analysis of S-phase enriched IncRNAs identifies oncogenic drivers and biomarkers, Nat. Commun. 9 (2018). doi:10.1038/s41467-018-03265-1.

[45] C. Adriaens, L. Standaert, J. Barra, M. Latil, A. Verfaillie, P. Kalev, B. Boeckx, P.W.G. Wijnhoven, E. Radaelli, W. Vermi, E. Leucci, G. Lapouge, B. Beck, J. van den Oord, S. Nakagawa, T. Hirose, A.A. Sablina, D. Lambrechts, S. Aerts, C. Blanpain, J.-C. Marine, p53 induces formation of NEAT1 IncRNA-containing paraspeckles that modulate replication stress response and chemosensitivity, Nat. Med. 22 (2016) 861-868. doi:10.1038/nm.4135.

[46] L. Jiang, C. Shao, Q.J. Wu, G. Chen, J. Zhou, B. Yang, H. Li, L.T. Gou, Y. Zhang, Y. Wang, G.W. Yeo, Y. Zhou, X.D. Fu, NEAT1 scaffolds RNA-binding proteins and the Microprocessor to globally enhance pri-miRNA processing, Nat. Struct. Mol. Biol. 24 (2017) 816-824. doi:10.1038/nsmb.3455.

[47•] D. Li, J. Zhang, M. Wang, X. Li, H. Gong, H. Tang, L. Chen, L. Wan, Q. Liu, Activity dependent LoNA regulates translation by coordinating rRNA transcription and methylation, Nat. Commun. 9 (2018). doi:10.1038/s41467-018-04072-4.

The authors demonstrate how a specific long non-coding RNA plays a pivitol role in regulating translation by coordinating rRNA transcription and methylation making this a target for cell engineering.

[48] C. Carrieri, L. Cimatti, M. Biagioli, A. Beugnet, S. Zucchelli, S. Fedele, E. Pesce, I. Ferrer, L. Collavin, C. Santoro, A.R.R. Forrest, P. Carninci, S. Biffo, E. Stupka, S. Gustincich, Long non-coding antisense RNA controls Uchl1 translation through an embedded SINEB2 repeat, Nature. (2012). doi:10.1038/nature11508.

[49] P. Podbevšek, F. Fasolo, C. Bon, L. Cimatti, S. Reißer, P. Carninci, G. Bussi, S. Zucchelli, 
J. Plavec, S. Gustincich, Structural determinants of the SINE B2 element embedded in the long non-coding RNA activator of translation AS Uchl1, Sci. Rep. 8 (2018) 1-13. doi:10.1038/s41598-017-14908-6.

[50••] L. Patrucco, A. Chiesa, M.F. Soluri, F. Fasolo, H. Takahashi, P. Carninci, S. Zucchelli, C. Santoro, S. Gustincich, D. Sblattero, D. Cotella, Engineering mammalian cell factories with SINEUP noncoding RNAs to improve translation of secreted proteins, Gene. 569 (2015) 287-293. doi:10.1016/j.gene.2015.05.070.

The authors report the first engineering of $\mathrm{CHO}$ cells with SINEUP long non-coding RNAs. They subsequently show that this resulted in enhanced translation of recombinant proteins and increased secretory yields, demonstrating the potential for cell engineering using this class of non-coding RNA.

[51•] Y. Yao, S. Jin, H. Long, Y. Yu, Z. Zhang, G. Cheng, C. Xu, Y. Ding, Q. Guan, N. Li, S. Fu, X.J. Chen, Y. Bin Yan, H. Zhang, P. Tong, Y. Tan, Y. Yu, S. Fu, J. Li, G.J. He, Q. Wu, RNAe: An effective method for targeted protein translation enhancement by artificial non-coding RNA with SINEB2 repeat, Nucleic Acids Res. 43 (2015). doi:10.1093/nar/gkv125.

The authors develop a 'universal' protein expression enhancer tool based upon long non-coding RNA elements. The authors identifed a minimal RNAe element which consists of a pairing sequence for specificity, a short non-pairing interspersed nuclear element that enhnaces ribosome recruitment and a polyA tail. The authors claim expression enhancement in various mammalian cells of recombinant proteins in the order of $50-1000 \%$.

[52] K.-C. Ou, C.-Y. Wang, K.-T. Liu, Y.-L. Chen, Y.-C. Chen, M.-D. Lai, M.-C. Yen, Optimization protein productivity of human interleukin-2 through codon usage, gene copy number and intracellular tRNA concentration in $\mathrm{CHO}$ cells, Biochem. Biophys. Res. Commun. 454 (2014) 347-352. doi:10.1016/j.bbrc.2014.10.097.

[53] G. Hanson, J. Coller, Translation and Protein Quality Control: Codon optimality, bias and usage in translation and mRNA decay, Nat. Rev. Mol. Cell Biol. 19 (2018) 20-30. doi:10.1038/nrm.2017.91.

[54] F. Zhao, C.-H. Yu, Y. Liu, Codon usage regulates protein structure and function by affecting translation elongation speed in Drosophila cells, Nucleic Acids Res. 45 (2017) 8484-8492. doi:10.1093/nar/gkx501.

[55] G. Magistrelli, Y. Poitevin, F. Schlosser, G. Pontini, P. Malinge, S. Josserand, M. Corbier, $\mathrm{N}$. Fischer, Optimizing assembly and production of native bispecific antibodies by codon de-optimization, MAbs. 9 (2017) 231-239. doi:10.1080/19420862.2016.1267088.

[56] G. Hanson, J. Coller, Codon optimality, bias and usage in translation and mRNA decay, Nat. Rev. Mol. Cell Biol. 19 (2017) 20-30. doi:10.1038/nrm.2017.91.

[57] V. Presnyak, N. Alhusaini, Y.-H. Chen, S. Martin, N. Morris, N. Kline, S. Olson, D. Weinberg, K.E. Baker, B.R. Graveley, J. Coller, Codon optimality is a major determinant of mRNA stability, Cell. 160 (2015) 1111-1124. doi:10.1016/j.cell.2015.02.029.

[58•] C.E. Gamble, C.E. Brule, K.M. Dean, S. Fields, E.J. Grayhack Correspondence, E.J. 
Grayhack, Adjacent codons act in concert to modulate translation efficiency in yeast, Cell. 166 (2016) 679-690. doi:10.1016/j.cell.2016.05.070.

The authors demonstrate in yeast how codon context is important in modulating translational efficiency and the imporatnce of considering codon usage in the context of the local environment and not as single codons alone.

[59] K.S. Ang, S. Kyriakopoulos, W. Li, D.-Y. Lee, Multi-omics data driven analysis establishes reference codon biases for synthetic gene design in microbial and mammalian cells, Methods. 102 (2016) 26-35. doi:10.1016/j.ymeth.2016.01.016.

[60] B.K.S. Chung, F.N.K. Yusufi, Mariati, Y. Yang, D.Y. Lee, Enhanced expression of codon optimized interferon gamma in CHO cells, J. Biotechnol. 167 (2013) 326-333. doi:10.1016/j.jbiotec.2013.07.011.

[61] T.E. Gorochowski, Z. Ignatova, R.A.L. Bovenberg, J.A. Roubos, Trade-offs between tRNA abundance and mRNA secondary structure support smoothing of translation elongation rate, Nucleic Acids Res. 43 (2015) 3022-3032. doi:10.1093/nar/gkv199.

[62] A.E. Cozen, E. Quartley, A.D. Holmes, E. Hrabeta-Robinson, E.M. Phizicky, T.M. Lowe, ARM-seq: AlkB-facilitated RNA methylation sequencing reveals a complex landscape of modified tRNA fragments, Nat. Methods. 12 (2015) 879-884. doi:10.1038/nmeth.3508.

[63] G. Zheng, Y. Qin, W.C. Clark, Q. Dai, C. Yi, C. He, A.M. Lambowitz, T. Pan, Efficient and quantitative high-throughput tRNA sequencing, Nat. Methods. 12 (2015) 835-837. doi:10.1038/nmeth.3478.

[64] M. Shigematsu, S. Honda, P. Loher, A.G. Telonis, I. Rigoutsos, Y. Kirino, YAMAT-seq: An efficient method for high-throughput sequencing of mature transfer RNAs, Nucleic Acids Res. 45 (2017) e70. doi:10.1093/nar/gkx005.

[65] T. Gogakos, M. Brown, A. Garzia, C. Meyer, M. Hafner, T. Tuschl, Characterizing expression and processing of precursor and mature human tRNAs by hydro-tRNAseq and PAR-CLIP, Cell Rep. 20 (2017) 1463-1475. doi:10.1016/j.celrep.2017.07.029.

[66] M.E. Evans, W.C. Clark, G. Zheng, T. Pan, Determination of tRNA aminoacylation levels by high-throughput sequencing, Nucleic Acids Res. 45 (2017). doi:10.1093/nar/gkx514.

[67] T. Pan, Modifications and functional genomics of human transfer RNA, Cell Res. 28 (2018) 395-404. doi:10.1038/s41422-018-0013-y.

[68] F. Liu, W. Clark, G. Luo, A. Klungland, X. Wang, Y. Fu, J. Wei, X. Wang, Z. Hao, Q. Dai, G. Zheng, H. Ma, D. Han, M. Evans, T. Pan, C. He, ALKBH1-mediated tRNA demethylation regulates translation, Cell. 167 (2016) 816-828. doi:10.1016/j.cell.2016.09.038.

[69] L. Kawarada, T. Suzuki, T. Ohira, S. Hirata, K. Miyauchi, T. Suzuki, ALKBH1 is an RNA dioxygenase responsible for cytoplasmic and mitochondrial tRNA modifications, Nucleic Acids Res. 45 (2017) 7401-7415. doi:10.1093/nar/gkx354.

[70] P. Kumar, C. Kuscu, A. Dutta, Biogenesis and function of transfer RNA-related fragments (tRFs), Trends Biochem. Sci. 41 (2016) 679-689. doi:10.1016/j.tibs.2016.05.004. 
Table 1. Summary of non-coding RNA cell engineering studies discussed in this review grouped by type of approach, with the reported experimental effect and the relative reference.

\begin{tabular}{|c|c|c|}
\hline Method & Effect & Reference \\
\hline \multirow[t]{4}{*}{ SIRNA } & $\begin{array}{l}\text { LDH-A activities were decreased by } 75-89 \% \text {, while the specific glucose consumption rates } \\
\text { reduced by } 54-87 \% \text { and the specific lactate production rates reduced to } 45-79 \% \text { of the } \\
\text { control cell line level. }\end{array}$ & [32] \\
\hline & $\begin{array}{l}\text { siRNA mediated inhibition of PDHKs and LDH-A in } \mathrm{CHO} \text { cells expressing a therapeutic } \\
\text { monoclonal antibody reduced lactate production, increased specific productivity and } \\
\text { volumetric antibody production by } 90 \%, 75 \% \text { and } 68 \% \text {, respectively. }\end{array}$ & [33] \\
\hline & $\begin{array}{l}\text { Ribosome profiling identified NeoR as a highly transcribed and translated gene in an IgG- } \\
\text { producing } \mathrm{CHO} \text { cell line. Viable cell concnetration was increased by } 35 \% \text { upon siRNA knock- } \\
\text { down of NeoR, which was accompanied by an } 18 \% \text { increase in product titer. }\end{array}$ & [34] \\
\hline & $\begin{array}{l}\text { Combined transient siRNA-mediated knockdown of the expression of the endoplasmic } \\
\text { reticulum localized proteins CerS2 and Tbc1D20 resulted in a } 50-66 \% \text { increase in specific } \\
\text { productivity of CHO-IgG cells. }\end{array}$ & [35] \\
\hline \multirow[t]{4}{*}{ miRNA } & $\begin{array}{l}\text { Co-expression of miR-557 and a difficult-to-express antibody resulted in a two-fold increase } \\
\text { in product titer. }\end{array}$ & [27] \\
\hline & miR-143 overexpression resulted in a $20 \%$ final increase in mAb productivity. & [28] \\
\hline & $\begin{array}{l}\text { Addition of a synthetic 3'UTR to destabilize DHFR expression allowed the generation of } \\
\text { stable DG44-derived cell pools expressing a model monoclonal antibody (mAb) with low MTX } \\
\text { concentrations. }\end{array}$ & [29] \\
\hline & $\begin{array}{l}\text { Inhibition of miR-124-3p and miR-19b-3p in } \mathrm{CHO} \text { increased } \mathrm{X} \text {-linked inhibitor of apoptosis } \\
\text { protein levels, enhancing } \mathrm{CHO} \text { cell growth and prolonged culture longevity while additionally } \\
\text { boosting productivity. }\end{array}$ & [31] \\
\hline \multirow[t]{2}{*}{ IncRNA } & $\begin{array}{l}\text { Engineering of } \mathrm{CHO} \text { cells with SINEUP long non-coding RNAs resulted in a } 150 \% \text { increase in } \\
\text { periostin levels in cell supernatant at } 72 \mathrm{~h} \text { post-transfection. }\end{array}$ & [50] \\
\hline & $\begin{array}{l}\text { The development of a 'universal' protein expression enhancer tool based upon long non- } \\
\text { coding RNAs gave expression enhancement in various mammalian cells of recombinant } \\
\text { proteinsin the order of } 50-1000 \% \text {, with more than } 200 \% \text { enhancement in most cases. }\end{array}$ & [51] \\
\hline \multirow[t]{3}{*}{$\begin{array}{c}\text { Codon } \\
\text { optimization }\end{array}$} & $\begin{array}{l}\text { Modification of human interleukin-2 (IL-2) through codons with high gene copy number and } \\
\text { high codon usage bias significantly increased protein productivity in CHO-K1 cells. }\end{array}$ & [52] \\
\hline & $\begin{array}{l}\text { Codon de-optimization of a bispecific antibody sequence through the introduction of less } \\
\text { frequently occurring codons in } \mathrm{CHO} \text { gave a } 2 \text {-fold final yield increase. }\end{array}$ & [55] \\
\hline & $\begin{array}{l}\text { In vivo expression of various codon context (CC) optimized IFN- } \gamma \text { in CHO cells exhibited at least } \\
\text { 13-fold increase in expression compared to the wild-type IFN- } \gamma \text { while a maximum of } 10 \text {-fold } \\
\text { increase was observed for the individual codon usage (ICU) optimized genes. }\end{array}$ & {$[60]$} \\
\hline
\end{tabular}

